\title{
Immune response of broiler breeder chickens to inactivated Avian influenza H5N1 vaccine under field condition
}

\author{
M. M. Amer ${ }^{1}$, A. El-H. A. Hanafie ${ }^{2}$, G. A. Zohair ${ }^{3}$. Wafaa-Abd-EL- \\ Ghany $^{1}$ \\ Poultry.Diseases, Depatrement, Faculty of Veterinary. Medicine, Cairo University ${ }^{1}$, El-Wadi \\ Poultry.Co., Giza, Egypt ${ }^{2}$, Faculty of Agriculture, Depatement. of Anim. Prod., Sana Univ., Yemen ${ }^{3}$
}

\begin{abstract}
This study was carried out on serum samples collected from broiler breeder chicken flocks vaccinated with avian influenza (AI) H5N1 inactivated vaccine. These flocks included 23 flocks aged 13 to 47 weeks reared in close houses in 7 sites; two vaccinated breeder flocks for HI antibody monitoring by 5 weeks interval samples and 8 flocks aged 41 weeks reared in different sites with identified females and males samples. The vaccine was used in a dose of $0.2 \mathrm{ml}$ at 1 day in hatchery and revaccinated with $0.5 \mathrm{ml}$ at age of 18 days, 19- 20 weeks and 40 weeks. Hemagglutination inhibition (HI) test was carried out against homologous antigen.

The study pointed out that AI H5N1 inactivated vaccine under field application induced irregular and low HI titres following the $1^{\text {st }}$ two doses ranged from $\log 20.0$ to 4.15 with great variation between flocks, where samples with titre 0-2 ranged from 20 to $100 \%$. The $3^{\text {rd }}$ dose at 19-20 weeks was essential to elevate $\mathrm{HI}$ titres 3.25 to 7.44 with more homogenizes flock immunity and lower percentage of titres $\mathbf{0 - 2}(\mathbf{0 - 2 0} \%)$ and as measured by HI test. Revaccination of layer flocks at 40 weeks (fourth dose) improves flock immunity facing stress of egg production as evaluated by HI (5.52 - 6.33) and lower negative percentage (5.5-11.7\%). Monitoring of breeder flock every 5 weeks is essential to detect proper time of revaccination as each flock has its HI antibody curve. There was a difference in $\mathrm{HI}$ tit re rang $\log 20.33$ to 1.2 between male and female chicks reared in the same house, but this variation not affecting flock mean.

Birds at aged 41 weeks having titres $<\log _{2}{ }^{3}$ (Seronegative) were protected when exposed to contact with infected flock as showed no clinical signs or change in HI titres after 12 days.

In conclusion the usage of homologous inactivated H5N1 vaccine in 4 doses in layer flocks was of value in improving chicken immunity to AI H5N1 wild strain circulate in our field.
\end{abstract}

Avian influenza $(\mathrm{AI})$ is a notifiable disease caused by influenza A viruses related to Family Orthomyxoviridae (Voyles, 2002). AI in domestic chickens and turkeys can be classify according to disease severity to severe; mortality rates in infected flocks often

approach $100 \%$; due to highly pathogenic AI (HPAI), and asymptomatic due to low-pathogenic AI (LPAI) (Horimoto and Kawaoka, 2001).

The OIE considered AI infection of poultry caused by any AI virus of the $\mathrm{H} 5$ or $\mathrm{H} 7$ subtypes or by any AI virus with an intravenous pathogenicity index (IVPI) greater than 1.2, and countries that identify HPAI should report the occurrence to OIE within 24 hours. (OIE, 2004).

AI virus subtypes are 16 different HA antigens and 9 different NA antigens. The last one HA types (H16) had been recognized, from black-headed gulls caught in Sweden and the Netherlands in 1999 (Fouchier et al., 2005).

H5N1 strains are of worldwide circulation in birds, are responsible for the current severe outbreaks in poultry, other birds, Human, feline and other mammals in Asia, Africa, Europe and USA (Keawcharoen et al., 2004, Thanawongnuwech et al., 2005; Webster et al., 2006).

Aquatic birds, particularly ducks, shore birds, and gulls, are considered the natural reservoirs for AI viruses (Webster et al., 1992 ; FAO/OIE/WHO, 2004). These birds generally do not develop disease when infected (Horimoto and Kawaoka 2001; Webster, et al., 2006); however, an outbreak of $\mathrm{H} 5 \mathrm{~N} 1$ was identified in migratory geese and other wild birds in Qinghai, China, May 2005 (Lui et al., 2005) and from asymptomatic free sparrows in Henan, China (Kou et al., 2005). Asymptomatically infected domestic ducks are shedding more $\mathrm{H}_{5} \mathrm{~N}_{1}$ virus for longer periods (WHO, 2004).

Since 1999, the number of occurring HPAI outbreaks has increased significantly (Capua et al., 2002). Outbreak of H5N1 1997 in Asian poultry in Hong Kong followed by a wide spread of the virus to poultry and humans. The outbreak 
was apparently stopped by slaughtering all domestic chickens (Snacken et al., 1999). The outbreak was reemerged in summer 2004 in several Asian areas and stormily spread toward Europe and Africa to reach Egypt and Nigeria in mid February 2006. This virus spread was attributed to Free ranging backyard chickens and ducks, illegal transportation of birds as well as infected migratory waterfowl ( $\mathrm{Li}$ et al., 2004; Chen et al., 2005; Liu et al., 2005; Tiensin et al., 2005; Webster et al., 2006).

Prevention of AI passed on strategies by APHIS (2002, FAO (2004) ; FAO/ OIE/WHO, (2005) as biosecurity to prevent exposure of flocks to the influenza virus; continuous monitoring; reporting of AI suspected and applying control measures; depopulation and disinfection and quarantine of positive cases as a short strategy (Stegeman et al., 2004). In endemic area, vaccination of poultry flocks by inactivated or gene vaccines became the only solution in the long-term strategy. Vaccination is targeting to lower losses from mortality, reduce the viral load in the environment and risk of human infection as well as eradication of positive cases (Luschow et al., 2001; FAO, 2004; OIE, 2005a; Van der Goot et al., 2005).

Two different types of inactivated (homologous $\mathrm{H}$ determinant and heterogonous $\mathrm{N}$ determinant) vaccines in oil-based emulsion are available for usage by injection (FAO, 2004). Infected chickens can yield positive hemagglutination inhibition (HI) antibody as early as 3 to 4 days after the appearance of first disease signs, HI- test can be useful as a serological test for diagnosis of the disease and evaluation of immune response of vaccinated chickens with inactivated vaccine as recommended by (Allan, 1981; Beck and Swayne 1997; OIE, 2004).

In Egypt, AI was under focus as enzootic cases of fowl plague had been reported 19231945 (Alexander, 1986 and 1992). The production of local vaccine was continued until complete diminish of disease at 1960s -1970s; where the production and use of vaccine was stopped. in mid February 2005 outbreaks of H5N1 had reported in backyard and commercial poultry flocks with human cases. Following the failure in "stamping out" both homologous Chinese (H5N1) and heterologus (H5N2), inactivated vaccines were used for prevention of the disease.

The usage of Chinese inactivated H5N1vaccine was followed by a storm of discussion about its activity and immunogenicity. Nowadays, both vaccines are used in poultry farms with reporting of considerable number of outbreaks.

From the above mention, our study planed to evaluate field application of the used homologous AI vaccine in immunizing breeder chicken flocks and estimate the post vaccinal immunity using HI-test with special consideration to the following. i) Detection of immune response of flocks reared in different locality, given the same vaccine and vaccination system, and at the same age. ii) Comparing the immunity curve in 2 flocks by testing 5 -week interval samples. iii) Comparing antibody levels in male and female birds of the same flock. iv) Ability of birds having undetected or low antibodies (considered seronegative) to contract infection in contact with naturally infected birds as a challenge.

\section{Materials and methods}

Serum samples. Random individual blood samples were collected for serum through wing vein of vaccinated chickens including: i) Vaccinated broiler breeder chicken flocks (23 flocks) aged 13 to 47 weeks of age as mixed sex samples. These flocks were reared in close houses in 7 sites with collection of 441 samples (17-20/flock) (Table 1 Fig. 1,2). ii) Two vaccinated breeder flocks were serologically monitored for AI H5 antibody response following vaccination in two flocks at (Table 2, Fig. 3,4)

a. The $1^{\text {st }}$ flock: $5^{\text {th }}$ to the $50^{\text {th }}$ week of age.

b. The $2^{\text {nd }}$ flock: $25^{\text {th }}$ to the $55^{\text {th }}$ week of age.

3. Identified numbered females (10-12) and males (2-5) from 8 flocks aged 41 weeks reared in different sites (Table 3, Fig. 5). Identified birds were kept in isolated pen until $\mathrm{HI}$ testing.

Contact infection. Seronegative 26 chicken of flocks 8-10 aged 18 weeks (Table 1) were subjected to contact infection by transfer them to infected vaccinated house; where most of sentinel birds were died. Sera from contact birds were collected and $\mathrm{HI}$ tested against H5N1 antigen 12 days later.

Positive and negative sera. Both negative and positive AI HI sera supplied by $\mathrm{H} 5 \mathrm{~N} 1$ vaccine producer used as serological test controls.

Antigen. H5N1, lyophilized antigen for HI tests supplied by the vaccine producer was used. The antigen was diluted in PBS and adjusted to $4 \mathrm{HI}$ units before use in evaluation of immune response (OIE, 2005).

HA and HI-tests. Methods recommended and described by OIE (2005b) were used to identify AI antigen or serological monitoring of immune 
response. HI result was interoperated as recommended by CEC (1992); OIE (2005). HIresults were given titre reference number (TRN) according Kaleta and Siegmann (1971).

Vaccines. The Chinese inactivated H5N1vaccine distributed by VACSERA, Agoza, Egypt was used in vaccination of chicken flocks.

Vaccination. Chickens were injected subcutaneously with the inactivated H5N1 oil adjuvant vaccine in the neck. The vaccine was used in a dose of $0.2 \mathrm{ml}$ at 1 day in hatchery and revaccinated with $0.5 \mathrm{ml}$ at age of 18 days, 19- 20 weeks and 40 weeks.

\section{Results}

Results of HI test (Table 1, Fig. 1) showing that flocks aged 13 weeks (6 flocks) were having variable titres ranging from 1.3 in flock 5 to 4.15 in flock 1. Flock number 15 showed HI mean titre 2.33, while flocks aging 18 weeks showed some what lower titres ranged from 0.0 (flock 20) to 3.87 (flock 14). Flocks 16 and 17 those received the $3^{\text {rd }}$ dose of vaccine showed increased HI titres 4.00 and 4.84; respectively. Flocks aged 26 weeks (18 and19) showed titres of 6.65 and 7.44 at the $7^{\text {th }}$ week post $3^{\text {rd }}$ vaccination. Chicken flocks aged 39 weeks (flock 20 and21) showed decreased titres to reach 3.66 and 3.25 ; respectively. Chicken flocks 22 and 23; those aged 47 weeks and given the 4th dose of vaccine at the $40^{\text {th }}$ week showed HI titres 6.33 and 5.52; respectively.

The repeated vaccination resulted in lowering in the percentage of birds showing titres $<\log _{2} 0$ 2 (Table 1 Fig.2) to be $20-100 \%$ in birds received 3 doses (flocks $1-15), 0-20 \%$ in 4 and 5 doses (flocks 16-23). The percentage of negative samples according to number of vaccine doses are 3 vaccine doses 140/293 (47.78\%), 4 vaccine doses $11 / 113(9.73 \%)$ and 5 vaccine doses $3 / 35$ $(8.57 \%)$.

Results in table 2 showing the HI titres in 5week interval in sera of vaccinated breeder flocks:

In flock 1 (Fig. 3 ) the mean HI $\log _{2}$ titres were 5.15 at the $5^{\text {th }}$ week of age (after 3 vaccination) then decreased to 3.50 at the $15^{\text {th }}$ and elevated from the week 20 following the $3^{\text {rd }}$ vaccination to reach the highest titre 6.25 at the week 25 . The HI titres decreased to 4.45 at the $40^{\text {th }}$ week of age, where the last AI vaccination which resulted in another increase in titre to 6.25 after 5 weeks.

In flock 2: The detected HI $\log _{2}$ titre was 7.30 at the 25 week and decreased to 4.95 at the $40^{\text {th }}$ week where the titre decrease was continue after the vaccination at $40^{\text {th }}$ week of age to be elevated at the $50^{\text {th }}$ week to reach 6.95 (Fig. 4). $\mathrm{HI}$ antibody curve is different in flock 1 and 2, but in both, there is a decline phase at age of 2540 weeks (maximum egg production).

Table (3) and Fig. (5) showed the HI titres in female and male chickens samples from 8 flocks aged 41 weeks one week following the $4^{\text {th }}$ vaccination. Male chickens samples having $\mathrm{HI}$ titres higher than females in 6 flocks 1,2 and 5-8, while titres of males were lower in flocks 2 and 3 . The difference in titres between the males and females was between $\log _{2} 0.33$ (flock 1) and 1.2 (flock 8). The variation between male and female titres is not affecting the flock means. The contact birds (Seronegative) showed no clinical signs or higher levels of HI titres after 12 days contact with the infected flock.

\section{Discussion}

Avian influenza (AI) H5N1 virus strains are of worldwide circulation in birds, responsible for the current severe outbreaks in poultry, other birds, Human, feline and other mammals in Asia, Africa, Europe and USA (Keawcharoen et al., 2004, Thanawongnuwech et al., 2005; Webster, et al., 2006). World human and animal health authorities (WHO, OIE and FAO) considered AI $\mathrm{H} 5 \mathrm{~N} 1$ as a notifiable disease required international cooperation on the scientific, information and economical to combat such infection and avoid the possible human pandemic.

Avian influenza prevention had been regular monitoring, hygienic measures to prevent infection and spread while control is based on eradication, disinfection quarantine and compensation (APHIS 2002; FAO, 2004; Stegeman et al., 2004; FAO/OIE/FAO, 2005a,b).

Vaccination is targeting to lower losses from clinical signs and mortality, reduce virus shedding and environmental load and risk of both poultry and human infection with continuous eradication of positive farms (Luschow et al., 2001; Swayne et al., 2000; FAO, 2004; OIE, 2005a; Van der Goot et al., 2005). Following the failure in stamping out both homologous (H5N1) and heterologus (H5N2), inactivated vaccines were used for prevention of the disease.

Serological testing, especially $\mathrm{HI}$ test is useful for evaluation of immune response of vaccinated chickens with inactivated vaccine (Allan, 1981; Beck and Swayne, 1997; OIE, 2004).

Our study to evaluate field application of the used $\mathrm{H} 5 \mathrm{~N} 1 \mathrm{AI}$ vaccine in immunizing breeder 
chicken flocks by HI-test using homologous $\mathrm{H}$ and $\mathrm{N}$ antigen supplied by the vaccine producer was carried out.

Results of HI test (Table 1, Fig. 1) showing that flocks aged 13 weeks (6 flocks) having variable titres ranging from 1.3 to 4.15 , while flocks aging 18 weeks showed also lower titres (0.0 to 3.87). Min et al., (2004) reported similar results where $\mathrm{HI}$ titre for inactivated $\mathrm{H} 5 \mathrm{~N} 1$ vaccine increased 14 days post vaccination to 27.5 and maintained at 25 level on day 210 and birds were resistant to challenge 18 days post vaccination.

Flocks received the $3^{\text {rd }}$ dose of vaccine (16 and 17) showed high HI titres (4.00 and 4.84) one week later, and flock 18 and 19 (6.65 and 7.44) at the $7^{\text {th }}$ week), respectively. While, chicken flocks aged 39 weeks (flock 20 and 21) showed lower titres (3.66 and 3.25); respectively. These results indicated that AI vaccines resulted in lower and irregular titres as stated by Salem (1995) who reported in constant antibody titres in vaccinated chickens and ranging from none to high titres.

Chicken flocks aged 47 weeks and given the $4^{\text {th }}$ dose of vaccine showed HI titres 5.52-6.33. This result showed that revaccination is important to obtain higher titres as mentioned by Stone (1987) used inactivated H5N2 vaccine in white leghorn layer chickens at 12 and 20 weeks, at 8 weeks post vaccination $\mathrm{HI}$ antibodies were 1/597 and protection was $90-100 \%$ and CEC (1992) who reported that birds vaccinated twice exhibited higher serological titres as compared to those vaccinated once. While Ai et al., (2004) reported that the highest antibody level against H9 (average 6.72) was observed at 31-80 days of age in 10 days vaccinated chickens.

The repeated vaccination resulted in lowering in the percentage of birds showing titres $<\log _{2} 0$ 2 (Table 1 Fig.2). Similar result hah been reported by Swayne et al., (2000) who concluded that commercial H5 AI vaccines could protect poultry from 1997 Hong Kong H5N1 strain, and the repeated vaccination is recommended for increase number of seropositive birds.

$\mathrm{HI}$ titres in 5-week interval sera of vaccinated breeder flocks, where in flock 1 (Fig. 3) the mean HI $\log _{2}$ titres were 5.15 at the $5^{\text {th }}$ week of age (after 2 vaccination) then decreased to 3.50 at the $15^{\text {th }}$ and elevated from the week 20 following the $3^{\text {rd }}$ vaccination to reach the highest titre 6.25 at the week 25. The HI titres decreased to 4.45 at the $40^{\text {th }}$ week of age, where the last AI vaccination which resulted in another increase in titre to 6.25 after 5 weeks. In flock 2: The detected HI $\log _{2}$ titre was 7.30 at the 25 week and decreased to 4.95 at the $40^{\text {th }}$ week where the titre decrease was continue after the vaccination at $40^{\text {th }}$ week of age to be elevated at the $50^{\text {th }}$ week to reach 6.95 (Fig. 4). HI antibody curve is different in flock 1 and 2, but in both, there is a decline phase at maximum egg production (age 25-40 weeks). These results proved that immune response to the same vaccine was differing with the flock and the repeated vaccination is essential to maintain high titres.

HI titres in female and male chickens flocks aged 41 weeks one week following the $4^{\text {th }}$ vaccination where, male chickens having $\mathrm{HI}$ titres generally varied from higher to lower from flock to anther. The difference in titres between the males and females was between $\log _{2} 0.33$ and 1.2. The variation between male and female titres is not affecting the flock means. This point needs more studies.

The contact birds (Seronegative) showed no clinical signs or higher levels of HI titres after 12 days contact with infected flock. This results are in agreement with results of Capua et al., (2002) who reported that birds having titres $<1: 2$ and 1:4 were died 4-6 days post H7N1 challenge. While, Swayne et al., (1999) reported that $41 \%$ of hi negative vaccinated chickens resist challenge and all chickens with detectable HI-titres were protected. The result can be explained by Swayne et al., (1999 and 2000) where the level of protection against mucosal infection and subsequent shedding of challenge virus may depend on the degree of sequence similarity between HA gene of vaccine and challenge virus. Moreover, Brugh and Stone (1986) reported that layer chickens had protected for 30 weeks after single vaccination.

This study pointed out that AI H5N1 inactivated vaccine under field application induced irregular and low $\mathrm{HI}$ titres following the $1^{\text {st }} 2$ doses and the $3^{\text {rd }}$ dose at 19-20 weeks was essential to elevate and homogenizes flock immunity as measured by $\mathrm{HI}$ test. Revaccination of layer flocks at 40 weeks improves flock immunity facing stress of egg production as evaluated by HI results and contact infection. 
Table (1): HI titres against $\mathrm{H5}$ in chicken flocks of different sites and ages.

\begin{tabular}{|c|c|c|c|c|c|c|c|c|c|c|c|c|}
\hline \multirow{2}{*}{$\begin{array}{l}\text { Flock } \\
\text { No } \\
\end{array}$} & \multirow{2}{*}{$\begin{array}{l}\text { Age } \\
/ \mathbf{w} \\
\end{array}$} & \multirow{2}{*}{$\begin{array}{l}\text { No of } \\
\text { samples }\end{array}$} & \multicolumn{7}{|c|}{ Distribution of HI - TRN } & \multirow{2}{*}{\multicolumn{2}{|c|}{ Mean \pm SD }} & \multirow{2}{*}{$\begin{array}{l}\% \\
0-2 \\
\end{array}$} \\
\hline & & & $0-2$ & 3 & 4 & 5 & 6 & 7 & 8 & & & \\
\hline 1 & & 20 & 4 & & 6 & 4 & 3 & 3 & & 4.15 & 2.36 & 20 \\
\hline 2 & & 17 & 6 & & 4 & 2 & 1 & 2 & 2 & 3.64 & 3.06 & 30 \\
\hline 3 & 13 & 20 & 8 & 2 & 2 & 8 & & & & 2.70 & 2.41 & 40 \\
\hline 4 & 15 & 20 & 8 & & 6 & 6 & & & & 2.90 & 2.13 & 40 \\
\hline 5 & & 20 & 17 & 2 & & & 1 & & & 1.30 & 2.00 & 80 \\
\hline 6 & & 18 & 9 & 2 & 2 & 4 & & & 1 & 2.33 & 2.61 & 50 \\
\hline 7 & 15 & 18 & 7 & 4 & 5 & 2 & & & & 2.33 & 2.00 & 38.8 \\
\hline 8 & & 20 & 10 & & 4 & & 2 & & & 2.78 & 2.11 & 50 \\
\hline 9 & & 20 & 4 & 2 & 10 & 2 & 2 & & & 3.67 & 1.73 & 20 \\
\hline 10 & & 20 & 12 & & 4 & 4 & & & & 2.22 & 2.28 & 60 \\
\hline 11 & & 20 & 12 & 2 & 2 & 4 & & & & 1.89 & 2.32 & 60 \\
\hline 12 & 18 & 20 & 6 & & 6 & 2 & 6 & & & 3.67 & 2.45 & 30 \\
\hline 13 & & 20 & 20 & & & & & & & 0.00 & 0.00 & 100 \\
\hline 14 & & 20 & 6 & & 6 & & 4 & & 4 & 3.78 & 3.23 & 30 \\
\hline 15 & & 20 & 12 & 2 & 6 & & & & & 1.67 & 2.00 & 60 \\
\hline 16 & & 18 & 3 & 1 & 5 & 5 & 4 & & & 4.00 & 2.02 & 16.6 \\
\hline 17 & 20 & 19 & 1 & 2 & 5 & 4 & 4 & 2 & 1 & 4.84 & 1.80 & 5.26 \\
\hline 18 & 26 & 20 & & 2 & 1 & 2 & 1 & 5 & 9 & 6.65 & 1.72 & 0.0 \\
\hline 19 & & 18 & & & & 1 & 2 & 3 & 12 & 7.44 & 0.92 & 0.0 \\
\hline 20 & & 18 & 3 & 2 & 6 & 6 & 1 & & & 3.66 & 1.84 & 16.6 \\
\hline 21 & 39 & 20 & 4 & 5 & 6 & 4 & 1 & & & 3.25 & 1.86 & 20 \\
\hline 22 & & 18 & 1 & & 3 & 1 & 2 & 3 & 8 & 6.33 & 2.19 & 5.5 \\
\hline 23 & $4 /$ & 17 & 2 & 3 & 1 & 1 & & 4 & 6 & 5.52 & 2.82 & 11.7 \\
\hline
\end{tabular}

SD: standard division.

TRN: titre reference number.

Table (2): Fife week's intervals monitoring of AI HI antibody titres in vaccinated breeder flocks.

\begin{tabular}{|c|c|c|c|c|c|c|c|c|c|c|}
\hline \multirow[b]{2}{*}{$\begin{array}{l}\text { Flock } \\
\text { No }\end{array}$} & \multirow{2}{*}{$\begin{array}{l}\text { Age/ } \\
\text { weeks }\end{array}$} & \multicolumn{4}{|c|}{ Distribution of $\mathrm{HI}$} & \multicolumn{3}{|c|}{ TRN - titre } & \multirow{2}{*}{\multicolumn{2}{|c|}{ Mean \pm SD }} \\
\hline & & $\begin{array}{l}0- \\
2\end{array}$ & 3 & 4 & 5 & 6 & 7 & 8 & & \\
\hline \multirow{10}{*}{1} & 5 & 2 & 2 & 4 & 4 & 1 & 1 & 6 & 5.15 & 2.52 \\
\hline & 10 & 2 & 3 & 4 & 4 & 4 & 1 & 2 & 4.60 & 2.16 \\
\hline & 15 & 4 & 2 & 5 & 6 & 2 & & 1 & 3.50 & 2.24 \\
\hline & 20 & 1 & 5 & 6 & 7 & 1 & & & 4.00 & 1.29 \\
\hline & 25 & & & 1 & 2 & 6 & 5 & 6 & 6.56 & 1.18 \\
\hline & 30 & & & 1 & 3 & 6 & 5 & 5 & 6.50 & 1.19 \\
\hline & 35 & & & 3 & 4 & 5 & 3 & 5 & 6.2 & 1.43 \\
\hline & 40 & 1 & 4 & 7 & 3 & 2 & 2 & 1 & 4.45 & 1.79 \\
\hline & 45 & & & 2 & 5 & 4 & 4 & 5 & 6.25 & 1.36 \\
\hline & 50 & & 2 & 3 & 8 & 4 & 2 & 1 & 5.20 & 1.28 \\
\hline \multirow{7}{*}{2} & 25 & & & & & 4 & 6 & 10 & 7.30 & 0.81 \\
\hline & 30 & & & 2 & 1 & 4 & 9 & 4 & 6.60 & 1.18 \\
\hline & 35 & & 2 & 2 & 4 & 8 & 2 & & 5.50 & 1.23 \\
\hline & 40 & & & & 6 & 10 & 3 & 1 & 4.95 & 0.83 \\
\hline & 45 & 2 & 2 & 8 & 4 & 4 & & & 4.10 & 1.68 \\
\hline & 50 & & & & 1 & 7 & 5 & 7 & 6.9 & 0.96 \\
\hline & 55 & & 4 & 8 & 2 & 3 & 2 & 1 & 4.7 & 1.49 \\
\hline
\end{tabular}

SD: standard division.

TRN: titre reference number. 
Table (3): Results of HI titre in Female samples compared with males of breeder flocks aged 41 weeks.

\begin{tabular}{|c|c|c|c|c|c|c|c|c|c|c|c|c|}
\hline \multirow{2}{*}{$\begin{array}{l}\text { Flock } \\
\text { No } \\
\end{array}$} & \multirow{2}{*}{ Sex } & \multirow{2}{*}{$\begin{array}{ll}\text { No of } \\
\text { samples }\end{array}$} & \multicolumn{7}{|c|}{ Distribution of HI - TRN } & \multirow{2}{*}{\multicolumn{2}{|c|}{ Mean \pm SD }} & \multirow{2}{*}{$\begin{array}{l}\text { Flock } \\
\text { mean } \\
\end{array}$} \\
\hline & & & $0-2$ & 3 & 4 & 5 & 6 & 7 & 8 & & & \\
\hline \multirow[t]{2}{*}{1} & Female & 12 & & & 1 & & & & 11 & $\begin{array}{l}7.6 \\
7\end{array}$ & 1.21 & 7.73 \\
\hline & Male & 3 & & & & & & & 3 & 8.00 & 0.00 & \\
\hline \multirow[t]{2}{*}{2} & Female & 10 & & & & & & 1 & 9 & $\begin{array}{l}7.9 \\
0\end{array}$ & 0.33 & 7.93 \\
\hline & Male & 4 & & & & & & & 4 & 8.00 & 0.00 & \\
\hline \multirow[t]{2}{*}{3} & Female & 12 & & & & 1 & & 2 & 9 & $\begin{array}{l}7.5 \\
8\end{array}$ & 0.93 & 731 \\
\hline & Male & 4 & & 1 & & & 2 & 1 & & 5.50 & 1.73 & \\
\hline \multirow[t]{2}{*}{4} & Female & 12 & & & & & & & 12 & $\begin{array}{l}8.0 \\
0\end{array}$ & 0.00 & 7.76 \\
\hline & Male & 5 & & & & & 2 & & 3 & 7.20 & 1.15 & \\
\hline \multirow[t]{2}{*}{5} & Female & 12 & & & 1 & & & 1 & 10 & $\begin{array}{l}7.5 \\
8\end{array}$ & 1.21 & 7.57 \\
\hline & Male & 2 & & & & & & & 2 & 8.00 & 0.00 & \\
\hline \multirow[t]{2}{*}{6} & Female & 12 & & & & & 3 & 2 & 7 & & 0.94 & 7.46 \\
\hline & Male & 3 & & & & & & & 3 & 8.00 & 0.00 & \\
\hline \multirow[t]{2}{*}{7} & Female & 12 & 1 & 1 & & & 1 & 9 & & $\begin{array}{l}6.1 \\
7\end{array}$ & 1.81 & 6.06 \\
\hline & Male & 3 & & & & 1 & 1 & & 1 & 6.33 & 1.53 & \\
\hline \multirow{2}{*}{8} & Female & 12 & & 1 & 1 & 1 & 3 & 6 & & & 1.38 & 6.35 \\
\hline & Male & 5 & & & & 1 & & 1 & 3 & 7.20 & 1.30 & \\
\hline
\end{tabular}

SD: standard division.

TRN: titre reference number

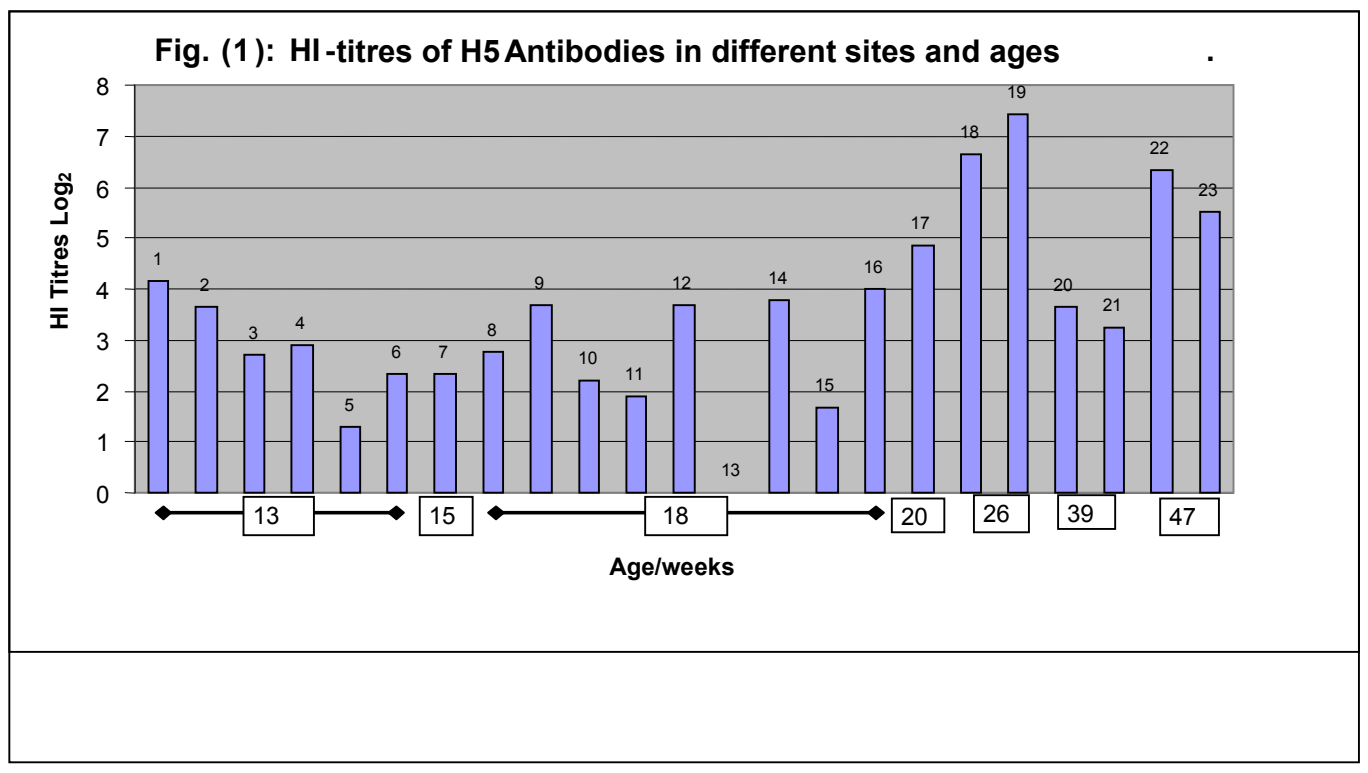



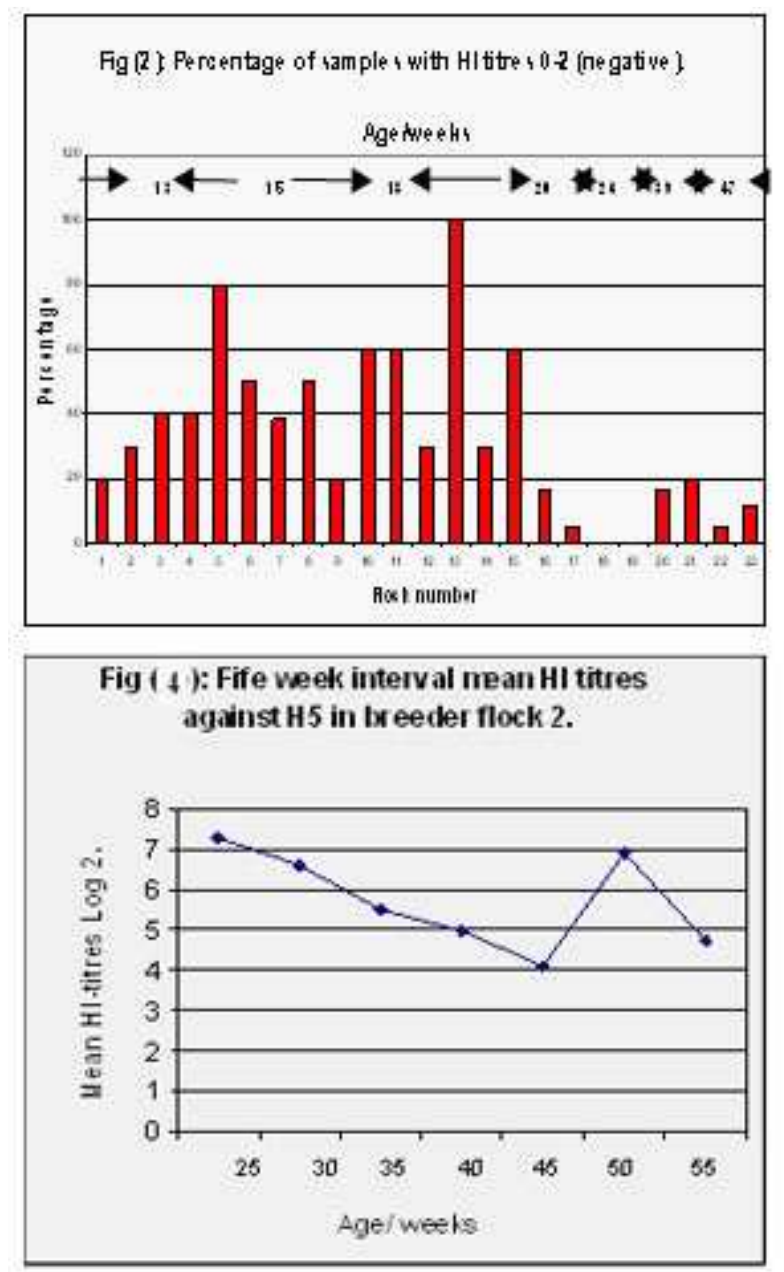

\section{References}

Alexander, D. J. (1986): Avian Influenza- Historical Aspects, in the Proc. of the $2^{\text {nd }}$ Internat. Symp. On Avian Influenza, Athens, Georgia, USA, U.S. Animal Health Assoc., 4 -13.

Alexander, D. J. (1992): Avian Influenza in the Eastern Hemisphere 1986-1992, in the Proc. of the $3^{\text {rd }}$ Internat. Symp. On Avian Influenza, Athens, Georgia, USA, U.S. Animal Health Assoc., 7 -19.

Allan, W. H. (1981): Diagnostic procedures - - Response. 1st.International Symposia on Avian Influenza,167-171.

APHIS, (2002): (Animal and Plant Health Inspection Service). Highly pathogenic avian influenza. Feb 2002.

Anon, (1971): Methods of examining poultry biologics and for identifying and quantifying avian pathogens. National Academy of Science, Washington, D.C.

Beck, R. J. and Swayne, E. D.(1997): Evaluation of ELISA for avian influenza serologic and diagnostic programs: Comparison with agar gel precipitin and hemagglutination inhibition tests. $4^{\text {th }}$.Int. Symp. Avian Influenza, 297- 303.

Brugh, M. and Stone, H. D. (1986): Inactivated avian influenza neuraminidase-specific vaccines in chickens. Proc. of the $2^{\text {nd }}$ Int. Symp. Avian Influenza, Athens, Georgia, USA., U.S. Animal Health Assoc., 283-292.

Capua, I. and Mutinelli, F. (2001): Mortality in Muscovy ducks (Cairina moschata) and domestic geese (Anser anser vur domestica) associated with natural infection with a highly pathogenic avian influenza virus of H7N1 subtype. Avian Pathol, 30(2)179-83.
Fig ( 3 ): Fite weehs intervalme an HItiters in brreder floch 1.

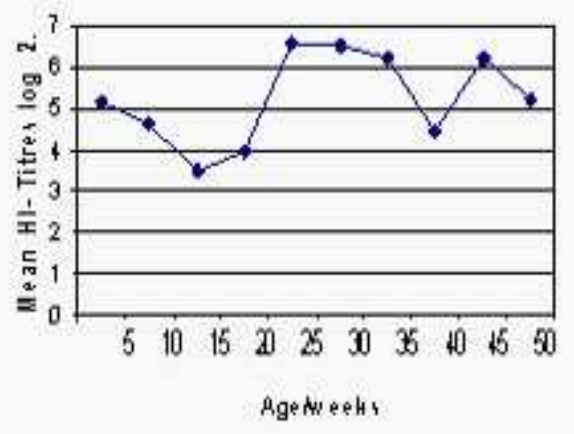

Fig (5): Female ( ) and male ( i i $\mathrm{HI}$ titres against $\mathrm{H} 5$ in breeder flocks aged 41

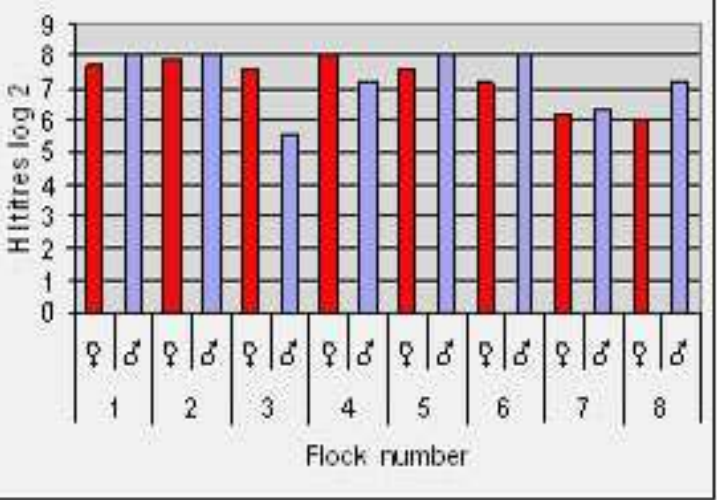

Capua, I.; Mutinelli, .F; Pozza, M. D.; Donatelli, I.; Puzelli, S. and Cancellotti, F. M. (2002): The 1999-2000 avian influenza (H7N1) epidemic in Italy: veterinary and human health implications. Acta-Tropica. 83(1): 7-11.

CEC, (1992): Council Directive 92/40 EEC of 19 May 1992 introducing community measures for the control of avian influenza. Official J. of the European commission, L 167:115.

Ai, C. R.; Fen, Z. W.; Hua, T. M.; Bo, P. H. and Lin, L. (2004): Improvement of the inactivated oil-emulsion vaccine against the AIV-H9 subtype of avian influenza. Chinese J. of Vet. Sci. and Technol. 34(1): 45-49.

Chen, H.; Smith, G. J. and Zhang, S.Y. (2005): Avian flu: $\mathrm{H} 5 \mathrm{~N} 1$ virus outbreak in migratory waterfowl. Nature ;436(7048):191-2.

FAO, (2004): Recommendations on the prevention, control, and eradication of highly pathogenic avian influenza (HPAI) in Asia.

FAO/OIE/WHO, (2004): Joint warning: domestic ducks could pose a new Avian influenza threat. 11,

FAO/OIE/WHO, (2005a): A global strategy for the progressive control of highly pathogenic avian influenza (HPAI).

FAO/OIE/WHO, (2005b): Consultation on avian influenza and human health: risk reduction measures in producing, marketing, and living with animals in Asia. Kuala Lumpur, Malaysia. Julie.

Fouchier, R. A. M.; Munster, V. and Wallensten A. (2005): Characterization of a novel influenza A virus hemagglutinin subtype (H16) obtained from black-headed gulls J Virol. ; 79(5):2814-2822 
Horimoto T. and Kawaoka Y. (2001): Pandemic threat posed by avian influenza A viruses. Clin. Microbiol. Rev.; 14(1):129-49

Keawcharoen, J.; Oraveerakul, K. and Kuiken T, (2004): Avian influenza H5N1 in tigers and leopards. Emerg. Infect. Dis. ;10(12)

Kaleta, E. F. and Siegmann, O. (1971) : Comparative studies on the demonistration of hemagglutinating inhibiting and virus neutralizingantibodies after vaccination against Newcastle disease. Arch. Geflugelk., 35:79.

Kou, Z.; Lei, F.M. and Yu, J. (2005): New genotype of avian influenza $\mathrm{H} 5 \mathrm{~N} 1$ viruses isolated from tree sparrows in China. J. Virol.; 79(24):15460-15466.

Li, K. S.; Guan, Y. and Wang, J. (2004): Genesis of a highly pathogenic and potentially pandemic $\mathrm{H} 5 \mathrm{~N} 1$ influenza virus in eastern Asia. Nature 8; 430:209-213.

Liu, J.; Xiao, H. and Lei, F. (2005): Highly pathogenic $\mathrm{H}_{5} \mathrm{~N}_{1}$ influenza virus infection in migratory birds. (Brevia) Science; 309:1206.

Luschow, D.; Werner O. and Mettenleiter T.C. (2001): Protections of chickens from lethal avian influenza A virus infections by live-virus hemagglutinin (H5) gene. Vaccine 20; 19(30):4249- 4259.

Min, W. H.; Cheng, H.; Ping, Z. J. and Peng, H. (2004): Studies on avian influenza inactivated vaccine of AIV$\mathrm{H}_{5} \mathrm{~N}_{1}$. J. of China Agric. Univ., 9 (1)41-44.

OIE, (2004): Highly pathogenic avian influenza. International Health Code. Chap 2.7.12.

OIE, (2005a): Evolution of the animal health situation with regard to avian influenza. ,

OIE, (2005b): Manual of diagnostic tests and vaccines for terrestrial animals: avian influenza. Chap. 2.7.12.

Salem, M.(1995): Avian influenza in Mexico. In Procc. of the $30^{\text {th }}$ National meeting on Poult. Health and Processing, Ocean City: Delmarva Poult. Indust.,99-105.

Snaken, R.; Kendal A. P. and Haaheim L. R. (1999): The next influenza pandemic: lesions from Hong Kong, 1997. Emerg. Infect. Dis.; 5(2):195-203

Stegeman A.; Bouma A. and Elbers, A. R. W. (2004): Avian influenza $A$ virus $\left(\mathrm{H}_{7} \mathrm{~N}_{7}\right)$ epidemic in The Netherlands in 2003: course of the epidemic and effectiveness of control measures. J. Infect. Dis. 15; 190:2088-2095.

Stone, H. D. (1987): Efficacy of Avian Influenza oilemulsion vaccines in chickens of various ages. Avian Dis., 31: 483-490.

Swayne, D. E.; Beck, R. J.; Garcia. M. and Stone D. A.(1999): Influence of virus strain and antigen mass on efficacy of $\mathrm{H} 5$ avian influenza inactivated vaccines. Avian Pathol. 28: 245-255.

Swayne, D. E.; Perdue, M. I.; Beck, R. J.; Garcia .M. and Suarez, D. L. (2000): Vaccines protect chickens against H5 highly pathogenic Avian influenza in the face of genetic changes in field viruses over multiple years. Vet. Microbiol. 74:165-172.

Tiensin, T.; Chaitaweesub, P. and Songserm ,T. (2005): Highly pathogenic avian influenza H5N1, Thailand. Emerg. Infect. Dis.; 11(11):1664-1672.

Thanawongnuwech, R.; Amonsin, A. and Tantilertcharoen, R. (2005): Probable tiger-to-tiger transmission of avian influenza H5N1. Emerg Infect Dis;11(5):699-701.

Vasti-Marandi, M.; Bozorgmehri-Fard, M. H. and Hashemzadeh, M. (2002): Effecacy of inactivated H9N2 avian influenza vaccine against non-highly pathogenic A/chicken/Iran/ZMT-173/1999 infection. Archives of Razi Inst. 53: 23-32.

Van Born, S.;Thomas, I, and Hanquet, G, (2005): Highly pathogenic H5N1 influenza virus in smuggled Thai Eagles, Belgium. Emerg. Infect. Dis.;11(5):702-705

Van der Goot, J. A.; Koch, G. and de Jong, M.C.M., (2005): Quantification of the effect of vaccination on transmission of avian influenza (H7N7) in chickens. Proc Natl. Acad. Sci. 13; 102(50):18141-18146.

Voyles, B. A. (2002): Orthomyxoviruses. In: The biology of viruses. $2^{\text {nd }}$ ed. New York, NY: McGraw-Hill,:147.

Webster, R. G.; Bean, W. J. and Gorman O.T. ( 1992):. Evolution and ecology of influenza A viruses. Microbiol. Rev. ;56:152-79.

Webster, R. G.; Peiris, M. and Chen H. I. (2006): $\mathrm{H}_{5} \mathrm{~N}_{1}$ outbreaks and enzootic influenza. Emerg. Infec.t Dis.;12 (1):3-8.

WHO, (2004): Laboratory study of $\mathrm{H} 5 \mathrm{~N} 1$ viruses in domestic ducks: main findings. 29.

WHO, (2005): Influenza pandemic preparedness and response. Jan 20.

WHO, (2005): Global Influenza Program Surveillance Network. Evolution of $\mathrm{H} 5 \mathrm{~N} 1$ avian influenza viruses in Asia. Emerg. Infect. Dis., 11(10):1515-1521

WHO, (2006): Avian influenza: situation (birds) in Nigeria. Feb 8.

Zanella, A.; Poli, G. and Bignami, M., (1981): Avian Influenza: Approaches in the Control of Disease with Inactivated Vaccines in Oil Emulsion, Proceedings of the first International Symposium on Avian Influenza, Beltsville, Maryland, USA. U.S. Animal Health Association, 180-183.

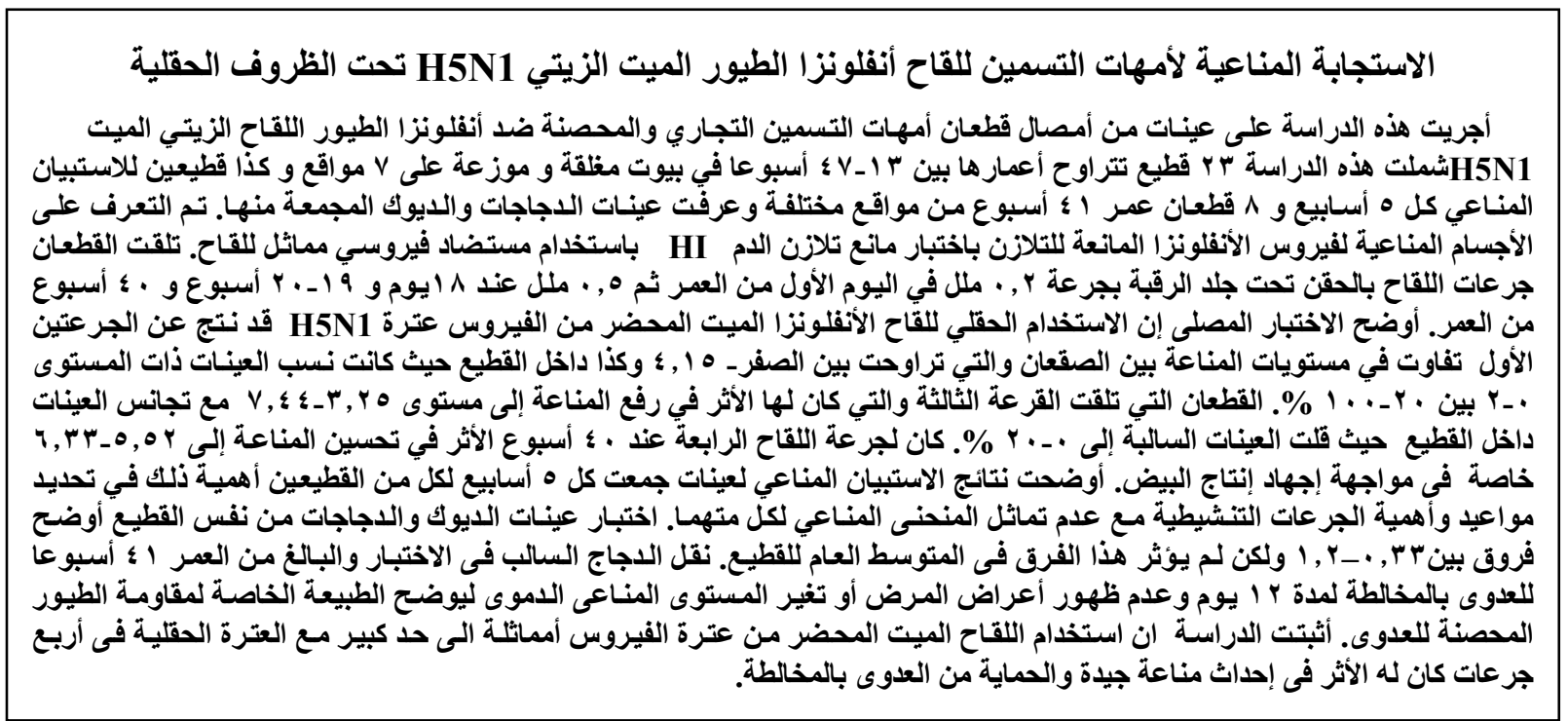


• 

